\title{
Incidence of AD in African-Americans, Caribbean Hispanics, and Caucasians in northern Manhattan
}

\author{
M.-X. Tang, PhD; P. Cross, Mphil; H. Andrews, PhD; D.M. Jacobs, PhD; S. Small, MD; K. Bell, MD; \\ C. Merchant, MD; R. Lantigua, MD; R. Costa, MA; Y. Stern, PhD; and R. Mayeux, MD, MSc
}

\begin{abstract}
Article abstract-Objective: To compare the incidence rates for $\mathrm{AD}$ among elderly African-American, Caribbean Hispanic, and white individuals and to determine whether coincident cerebrovascular disease contributes to the inconsistency in reported differences among ethnic groups. Methods: This was a population-based, longitudinal study over a 7-year period in the Washington Heights and Inwood communities of New York City. Annual incidence rates for AD were calculated and compared by ethnic group, and cumulative incidence adjusted for differences in education, diabetes, cardiovascular risk factors, and stroke was calculated. Results: The age-specific incidence rate for probable and possible $\mathrm{AD}$ was $1.3 \%$ (95\% CI, 0.8 to 1.7) per person-year between the ages of 65 and 74 years, $4.0 \%$ (95\% CI, 3.2 to 4.8 ) per person-year between ages 75 and 84 years, and 7.9\% (95\% CI, 5.5 to 10.5) per person-year for ages 85 and older. Compared to white individuals, the cumulative incidence of $\mathrm{AD}$ to age 90 years was increased twofold among African-American and Caribbean Hispanic individuals. Adjustment for differences in number of years of education, illiteracy, or a history of stroke, hypertension, heart disease, or diabetes did not change the disproportionate risks among the three ethnic groups. Conclusion: The incidence rate for $\mathrm{AD}$ was significantly higher among African-American and Caribbean Hispanic elderly individuals compared white individuals. The presence of clinically apparent cardiovascular or cerebrovascular disease did not contribute to the increased risk of disease. Because the proportion of African-American and Caribbean Hispanic individuals reaching ages 65 and older in the United States is increasing more rapidly than the proportion of white individuals, it is imperative that this disparity in health among the elderly be understood.
\end{abstract}

NEUROLOGY 2001;56:49-56

Prevalence and incidence rates for $\mathrm{AD}$ have been studied extensively throughout the world. ${ }^{1-20}$ Despite methodologic differences in these studies, most have shown a consistent rise in the frequency of $\mathrm{AD}$ with increasing age. Women appear to have a higher frequency of $\mathrm{AD}$ than men in some, but not all studies..$^{17,19,21-23}$ Although the prevalence and incidence rates for dementia in Asia, China, Europe, and the United States are comparable, the types of dementia can vary. For example, the frequency of vascular dementia is reported to be higher than that of $\mathrm{AD}$ among East Asians ${ }^{13}$ and JapaneseAmericans ${ }^{18}$ compared with most populations in the United States and Europe.

Only a few studies in the United States have compared the frequency of $\mathrm{AD}$ or other forms of dementia among major ethnic groups. No differences in the prevalence and incidence rates of $\mathrm{AD}$ were reported among African-American and white individuals in the Piedmont area of North Carolina participating in the Duke Established Populations for Epidemiologic
Studies of the Elderly. ${ }^{5}$ However, Gurland et al. ${ }^{8}$ reported a higher prevalence of all types of dementia, including AD, among African-American and Hispanic individuals compared with white individuals in northern Manhattan in a case registry and in a probability sample. In Houston, both prevalence and incidence rates for $\mathrm{AD}$ were higher in African-American and Hispanic retired municipal employees than in white retirees. ${ }^{16}$ Two postmortem studies ${ }^{24,25}$ provide conflicting results. Consecutive autopsies over an 18month period performed at the University of Michigan Medical Center among individuals aged 65 years and older revealed no differences in the frequency of postmortem changes associated with $\mathrm{AD}$ among African-American and white individuals. ${ }^{24}$ In contrast, a study in Baltimore ${ }^{25}$ found significantly more pathologic changes consistent with $\mathrm{AD}$ pathology among white individuals compared with AfricanAmerican individuals with or without a diagnosis of dementia.

From the Taub Institute for Research on Alzheimer's Disease and the Aging Brain (Drs. Tang, Andrews, Jacobs, Small, Bell, Merchant, Lantigua, Stern, Mayeux, and R. Costa), the Gertrude H. Sergievsky Center (Drs. Tang, Andrews, Jacobs, Small, Bell, Merchant, Stern, Mayeux, and R. Costa), and the Departments of Neurology (Drs. Jacobs, Small, Bell, Merchant, Stern, Mayeux, and R. Costa), Psychiatry (Drs. Stern and Mayeux), and Medicine (Dr. Lantigua), College of Physicians and Surgeons, and the Divisions of Epidemiology (Dr. Mayeux), Biostatistics (Dr. Tang), and Sociomedical Sciences (Dr. Andrews), School of Public Health, Columbia University; and the Epidemiology of Mental Disorders Research Department (Dr. Cross), New York State Psychiatric Institute, New York.

Supported by federal grants from the NIH (AG07232 and AG08702), by the Charles S. Robertson Memorial Gift for Research on AD, and by the Blanchette Hooker Rockefeller Foundation.

Received July 17, 2000. Accepted in final form October 10, 2000.

Address correspondence and reprint requests to Dr. R. Mayeux, Gertrude H. Sergievsky Center, 630 West 168th Street, Columbia University, New York, NY 10032; e-mail: rpm2@columbia.edu 
It is unclear whether the conflicting results of these studies are due to different methods of diagnosis and case ascertainment, or confounding factors such as hypertension, stroke, or heart disease. Crosssectional studies cannot provide information concerning the development of $\mathrm{AD}$, and many previous studies failed to carefully examine the contributions of cardiovascular risk factors and stroke. The current study provides new information comparing the incidence rates of newly diagnosed $\mathrm{AD}$ over a 7-year period from 1992 to 1999 in a community-based study of African-American, Caribbean Hispanic, and white elderly individuals residing in the communities of Washington Heights and Inwood in northern Manhattan, New York City. ${ }^{8}$

Materials and methods. Subjects and setting. The cohort was identified from a probability sample of Medicare beneficiaries residing in an area of three contiguous census tracts in the northern Manhattan communities of Washington Heights and Inwood in New York City, an area from 151st Street North to 181st Street, bounded by the Hudson and Harlem rivers. Access to the names of individuals was provided by The Health Care Financing Administration (HCFA). Before recruitment, each individual was sent a joint letter explaining that they had been selected to participate in a study of aging. The original HCFA list of 5,403 names was divided into six strata based on ethnic group and age (65 to 74 years and 75 years and older). We used HCFA data, supplemented by 1990 US Census files that included a Hispanic surname list, to categorize ethnic group. This allowed a tentative designation as AfricanAmerican (non-Hispanic), white (non Hispanic), and Hispanic. These strata were further divided into 37 representative subsamples so that the distributions by ethnic group and age within each subsample would be similar. This provided the means to ensure equal representation of the community during the initial assessment of participants.

We determined that $896(16.6 \%)$ of the original 5,403 individuals had moved from the region and that 470 (8.7\%) were dead. Another 409 (7.6\%) could not be located despite numerous attempts to contact them by telephone, regular mail, and letters dropped off at the address provided by HCFA. The proportion of individuals in each age strata not located or found to be deceased was similar across the three ethnic groups. An additional 176 (3.3\%) were either ineligible (younger than 65 years of age), did not reside in the community during the baseline study period, or spoke languages other than English or Spanish. One thousand, three hundred twenty-four (25\%) refused to participate in the study. Excluding those who died, the proportion of individuals in each age stratum that did not wish to participate for any reason, including refusal, did not differ by ethnic group. Two individuals were duplicated in the database under different names. Data from 2,126 (62\%) of the 3,452 eligible individuals were included in the baseline assessment. Based on the distributions within the 37 subsamples, the proportion of individuals within each ethnic group and age stratum who participated in the study did not differ significantly from the source population.

The Columbia University Institutional Review Board reviewed and approved this project. All individuals provided written informed consent.
Ethnic group. At the baseline interview, ethnic group was confirmed by self-report using the format of the 1990 US Census. ${ }^{26}$ Briefly, each individual was first asked to indicate his or her racial group, then asked whether or not he was of "Hispanic" origin. Mixed category was not a category in the 1990 US Census. This again confirmed the separation into three groups: "black" (African-American, non-Hispanic), "white" (non-Hispanic), or "Hispanic." Hispanic individuals, therefore, could be either black or white. For Hispanic individuals, we also asked for country of birth or origin.

Clinical assessments. Detailed clinical assessments were completed at approximately 24-month intervals over the 7-year study period. All interviews were conducted in either English or Spanish. The choice of language was decided by the subject in order to ensure the best performance, and the majority of assessments were performed in the subject's home. The maximum number of assessments was four (baseline and three follow-up visits). Individuals in the first four subsamples (12\% of the cohort) underwent a detailed general health interview that included a cognitive test, the Care-Diagnostic Interview, ${ }^{27}$ and an assessment of the ability to perform activities of daily life. A standardized medical, neurologic, and neuropsychological examination, which is described below, was also completed. ${ }^{28,29}$ In the remaining 33 subsamples, we used a twostage procedure. Based on the results from the first four subsamples, we determined that the probability of dementia among individuals with a Care-Diagnostic Interview score below 3 was $6 \%$. Therefore, only those subjects with a Care-Diagnostic Interview score of 3 or higher and 25\% random sample of those who with scores below 3 underwent the detailed examination described above in the first four subsamples ( $\mathrm{n}=1,072 ; 50.4 \%)$. However, for all follow-up assessments, every subject, regardless of CareDiagnostic Interview score, received the complete clinical examination described below.

The detailed clinical assessment included a standardized medical and neurologic history and examination by a trained physician. Medical diagnoses were assigned when applicable and a tentative diagnosis of dementia, if deemed appropriate, was made without benefit of neuropsychological testing. This examination was repeated at each follow-up visit.

The tests comprising the neuropsychological battery were chosen because they represented several domains. Orientation was tested using items from the modified Mini-Mental State Examination. ${ }^{30}$ Language was examined using the Boston Naming Test, ${ }^{31}$ the Controlled Word Association test, ${ }^{32}$ category naming, and the Complex Ideational Material and Phrase Repetition subtests of the Boston Diagnostic Aphasia Evaluation. ${ }^{33}$ Abstract Reasoning and Similarities subtests from the Wechsler Adult Intelligence Scale-Revised ${ }^{34}$ and the nonverbal Similarities subtest of the Mattis Dementia Rating Scale ${ }^{35}$ were used to assess general reasoning ability. Visuospatial ability was examined using the Rosen Drawing Test ${ }^{36}$ and a matching version of the Benton Visual Retention Test. ${ }^{37}$ Memory was evaluated using the multiple-choice version of the Benton Visual Retention Test and the Selective Reminding Test. ${ }^{38}$ The time to complete the entire test battery ranged from 45 to 90 minutes. 
Table 1 Demographic characteristics of follow-up cohort $(n=1788)$

\begin{tabular}{|c|c|c|c|}
\hline Characteristics & $\begin{array}{l}\text { African-American } \\
\quad(\mathrm{n}=610)\end{array}$ & $\begin{array}{l}\text { Caribbean Hispanic } \\
\qquad(\mathrm{n}=760)\end{array}$ & $\begin{array}{c}\text { White } \\
(\mathrm{n}=418)\end{array}$ \\
\hline Age, y, mean $(\mathrm{SD}) *$ & $75.8(6.2)$ & $74.9(5.8)$ & $76.9(7.2)$ \\
\hline Women, \% & 71 & 68 & 65 \\
\hline Duration of follow-up, y, mean (SD) & $4.3(1.5)$ & $4.4(1.4)$ & $4.3(1.5)$ \\
\hline Stroke & 9.7 & 9.4 & 9.1 \\
\hline Diabetes $\ddagger$ & 18.7 & 22.1 & 10.3 \\
\hline Heart disease§ & 25 & 33 & 29 \\
\hline Hypertensionף & 59 & 62 & 45 \\
\hline
\end{tabular}

$* p=0.001$. White individuals were older than African-Americans and Caribbean Hispanics.

$\dagger p=0.001$. White individuals had more years of education than either African-Americans or Caribbean Hispanics; African-Americans had more years of education than Caribbean Hispanics.

$\$$ Diabetes was more frequent among African-Americans and Caribbean Hispanics than among white individuals.

$\S p=0.01$. Heart disease was more frequent among Caribbean Hispanics than African-Americans. Neither of these two groups differed from white individuals.

II $p=0.001$. Hypertension was more frequent among African-Americans and Caribbean Hispanics than among white individuals.

Results of the medical and neurologic examinations and neuropsychological testing, including any tentative diagnoses, were reviewed after each completed follow-up assessment by a group of neurologists, psychiatrists, and neuropsychologists, who reached consensus regarding the presence or absence of dementia. Members of the consensus group were blinded to information regarding ethnicity. The reliability of this approach had been established earlier. ${ }^{28,39}$ Participants meeting criteria for dementia were further subclassified according to published criteria for probable and possible $\mathrm{AD}^{40}$ and vascular dementia. ${ }^{41}$ For other types of dementia, we used a standardized protocol for diagnosis (available upon request). Severity of dementia for individuals with $\mathrm{AD}$ was rated using the Clinical Dementia Rating Scale ${ }^{42}$ at the time of the consensus conference. Individuals who performed within the normal ranges for age and education previously established in the community ${ }^{43}$ were considered unaffected at the date of that assessment.

Data analysis. Age, ethnic group, and education level were compared among those who did and did not develop $\mathrm{AD}$ or another forms of dementia using $\chi^{2}$ tests for categorical variables, and analysis of variance and Student's $t$-test for continuous variables. To determine incidence rates, we calculated the period from the baseline assessment to each subsequent follow-up assessment for every individual. Thus, all participants contributed to the total number of person-years until they either became demented, died, or were lost to follow-up. The incidence rate was calculated by dividing the number of new cases (e.g., $\mathrm{AD}$ ) by the total number of person-years of follow-up. Incidence rates were calculated within strata defined by age categories (65 to 74 years, 75 to 84 years, and 85 years and older), by years of education (stratified by the median of 8 years), and by ethnic group (as defined above). For the calculation of incidence rates, we considered cases that met published critieria $^{40}$ only when they had a Clinical Dementia Rating Scale $^{42}$ score of 1.0 or higher for probable and possible AD. Individuals with Clinical Dementia Rating Scale scores below 1.0 were included as "unaffected." We compared the incidence rates between the ethnic groups by calculating the standardized rate ratio with $95 \% \mathrm{CI}$, using white individuals as the referent group from which weights were derived for the calculations. ${ }^{44}$

The Cox proportional hazard model ${ }^{45}$ was used to compute the hazard ratio (HR) for $\mathrm{AD}$. As has been recommended for longitudinal investigations, ${ }^{46}$ the time to event variable was age at onset of $\mathrm{AD}$, requiring no further age adjustment. Among those who did not develop $\mathrm{AD}$, we right-censored at the age at death, age at the last examination, or the age at which another form of dementia was identified. Survival analysis was used to plot the cumulative incidence of $\mathrm{AD}$ by age. Relative risks were calculated for each ethnic group and adjusted by years of education using white individuals as the referent group. Subsequent proportional hazard models included the presence or absence of diabetes, hypertension, heart disease, or stroke in order to estimate the HR adjusting for a history of cardiovascular or cerebrovascular disease by ethnic group. The proportional hazards assumptions were evaluated using a modified Martingale method. ${ }^{47}$

Results. Among the 2,126 participants, 327 (15.4\%) were demented at baseline. This left 1,799 without dementia eligible for follow-up. In the cohort, $34.1 \%$ of individuals identified themselves as African-American, $23.4 \%$ as white, and $42.5 \%$ as Hispanic. The majority (84\%) of those identified as Hispanic were of Caribbean origin and 54\% were from the Dominican Republic. The remaining individuals described as Hispanic were from Puerto Rico, Cuba, Mexico, and Central America. Eleven individuals were from a variety of other ethnic groups, and their data were excluded from the analysis comparing ethnic groups, leaving 1,788 participants. The demographic characteristics of this follow-up cohort are shown in table 1. Similarities and differences in the frequency of stroke, diabetes, hypertension, and heart disease are also shown in table 1. AfricanAmerican and Caribbean Hispanic elderly individuals were slightly younger and less educated than white elderly individuals. African-American individuals were slightly, 
Table 2 Age-specific incidence rates for probable and possible AD by ethnic group

\begin{tabular}{|c|c|c|c|c|}
\hline $\begin{array}{l}\text { Age group, y/ethnic } \\
\text { group }\end{array}$ & $\begin{array}{l}\text { Person-years } \\
\text { at risk }\end{array}$ & Incident $\mathrm{AD}$ & $\begin{array}{l}\text { Incidence rate per } \\
\text { person-year, \% }\end{array}$ & $95 \% \mathrm{CI}$ \\
\hline \multicolumn{5}{|l|}{65 to 74} \\
\hline Caribbean Hispanic & $1,264.97$ & 18 & 1.4 & $0.8-2.1$ \\
\hline White & 489.24 & 2 & 0.4 & $0.1-0.9$ \\
\hline African-American & 736.14 & 32 & 4.4 & $2.9-5.8$ \\
\hline Caribbean Hispanic & 937.15 & 42 & 4.4 & $3.1-5.8$ \\
\hline White & 494.93 & 13 & 2.6 & $1.2-4.0$ \\
\hline \multicolumn{5}{|l|}{85 and older } \\
\hline African-American & 148.82 & 17 & 11.4 & $6.3-16.5$ \\
\hline All groups & $5,152.97$ & 156 & 3.0 & $2.5-3.5$ \\
\hline
\end{tabular}

but significantly older and better educated than Caribbean Hispanic individuals.

Diabetes and hypertension were more prevalent among African-American and Caribbean Hispanic elderly individuals than among white individuals (see table 1), but there was no difference in the frequency of these disorders between these two groups. The frequency of heart disease was higher among Caribbean Hispanic and white individuals than among African-American individuals.

Probable or possible $\mathrm{AD}$ developed in 156 individuals (8.7\% overall; 130 probable, 26 possible), vascular dementia in $36(2.0 \%)$, and other dementia in $20(1.1 \%)$ over the entire follow-up period. Probable or possible AD occurred significantly more frequently among African-American (10.5\%) and Hispanic $(9.8 \%)$ individuals than in white $(5.4 \%)$ individuals $\left(\chi^{2}=10.5, d f[2], p=0.03\right)$, but the proportion of cases with probable or possible $\mathrm{AD}$ was similar within ethnic groups. The frequency of vascular dementia was not different among African-American (2.6\%) and Hispanic $(2.7 \%)$ individuals compared with white $(1.0 \%)$ individuals $\left(\chi^{2}=3.4, d f[2], p=0.2\right)$. The frequency of other dementias was also similar across the ethnic groups. Losses due to death averaged $4.9 \%$ per year, losses due to refusal to continue participation averaged $6.3 \%$ per year, and losses to follow-up averaged $4.8 \%$ per year. None of these rates differed by ethnic group nor did they vary by study interval.

Incidence rates of $A D$. The age-specific incidence rate for probable and possible $\mathrm{AD}$ was $1.3 \%$ (95\% CI, 0.8 to 1.7 ) per person-year between the ages of 65 and 74 years, $4.0 \%$ (95\% CI, 3.2 to 4.8 ) per person-year between ages 75 and 84 years, and $7.9 \%$ (95\% CI, 5.5 to 10.5 ) per person-year for ages 85 years and older. There were significant differences in the age-specific incidence rates for $\mathrm{AD}$ by ethnic group (table 2; figure). The incidence rate among the 1,054 individuals who had received only the Care-Diagnostic Interview at baseline (all with scores below 3) was calculated separately before including their data with the 1,072 that received the entire assessment in the overall rates. The age-specific incidence rates in these two groups did not differ significantly from those in table 2.

Standardized rate ratios (SRR) were calculated to compare the overall incidence rates of $\mathrm{AD}$ between the three ethnic groups, using white individuals as the referent ethnic group. The age-specific incidence rates shown in table 2 for African-American and Hispanic individuals were weighted by the proportion of person-years of follow-up for white individuals. The overall crude incidence rate for white individuals was $1.9 \%$ per person-year. The standardized incidence rate for African-American individuals was $4.2 \%$ per person-year ( $\mathrm{SRR}=2.2 ; 95 \% \mathrm{CI}, 1.4$ to 3.6$)$. The standardized incidence rate for Caribbean Hispanics was $3.8 \%$ per person-year ( $\mathrm{SRR}=2.0 ; 95 \% \mathrm{CI}, 1.2$ to 3.2 ). Thus, compared with white individuals in the same community, the incidence rates for African-American and Caribbean Hispanic individuals was increased twofold.

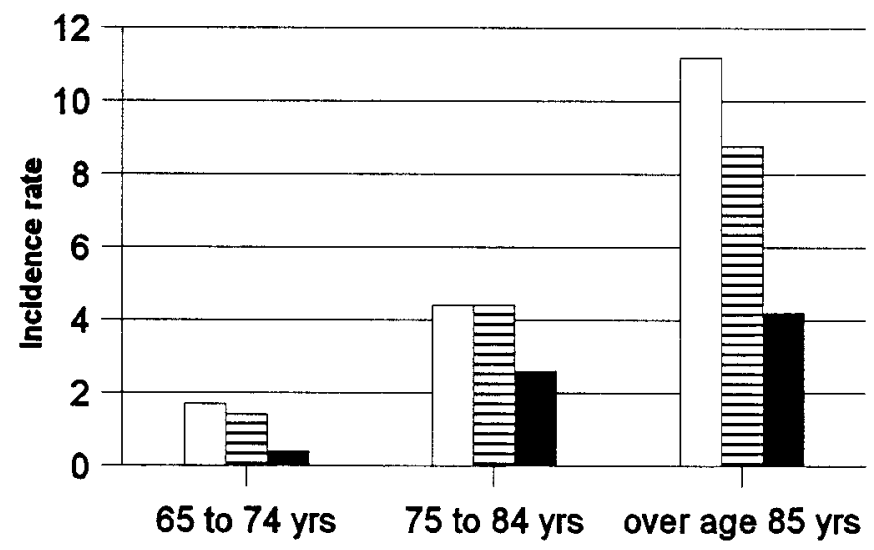

Figure. Annual age-specific incidence rates for $A D$ among African-American, Caribbean Hispanic, and white elderly Medicare recipients in northern Manhattan. Black bars = white individuals; white bars = African-American individuals; striped bars $=$ Caribbean Hispanic individuals. 
Table 3 Comparison of hazard ratios (HR) for probable and possible $A D$ by ethnic group

\begin{tabular}{|c|c|c|c|}
\hline Total at risk & $\begin{array}{l}\mathrm{AD}, \mathrm{n} \\
(\%)\end{array}$ & $\begin{array}{l}\text { Model 1, HR } \\
\quad(95 \% \text { CI })\end{array}$ & $\begin{array}{l}\text { Model 2, HR } \\
\quad(95 \% \text { CI })\end{array}$ \\
\hline \multicolumn{4}{|l|}{ By ethnic group* } \\
\hline $\begin{array}{l}\text { White } \\
(\mathrm{n}=418)\end{array}$ & $22(5.4)$ & 1.0 (reference) & 1.0 (reference) \\
\hline $\begin{array}{l}\text { Black } \\
(\mathrm{n}=610)\end{array}$ & $64(10.5)$ & $2.6(1.6-4.2) \dagger$ & $2.4(1.5-4.0) \dagger$ \\
\hline $\begin{array}{l}\text { Caribbean Hispanic } \\
(\mathrm{n}=760)\end{array}$ & $70(9.8)$ & $2.3(1.4-3.8) \dagger$ & $2.0(1.2-3.4) \ddagger$ \\
\hline Education & & $0.94(0.90-0.98)+$ & $0.94(0.9-0.98) \ddagger$ \\
\hline \multicolumn{4}{|l|}{ History } \\
\hline Stroke & & & $0.9(0.5-1.6)$ \\
\hline Diabetes & & & $1.6(1.1-2.3) \S$ \\
\hline Heart disease & & & $1.1(0.8-1.6)$ \\
\hline Hypertension & & & $1.4(0.9-1.9)$ \\
\hline
\end{tabular}

"AD" includes both probable and possible $\mathrm{AD}$.

* Excludes 20 individuals who developed other forms of dementia and 36 who developed vascular dementia.

$\dagger \mathrm{p} \leq 0.001 ; \neq \mathrm{p} \leq 0.01 ; \S \mathrm{p} \leq 0.05$.

We recalculated the incidence rates limiting the case definition to probable $\mathrm{AD}(\mathrm{n}=130)$ to decrease the possibility that the higher rates among African-American and Caribbean Hispanic individuals were due to comorbid illness, but the differences in incidence rates compared with white individuals remained unchanged.

Age-specific incidence rates for vascular dementia overall varied from $0.47 \%$ (95\% CI, 0.21 to 0.74 ) per personyear between the ages of 65 and 74 years, $0.8 \%$ (95\% CI, 0.45 to 1.2) per person-year between ages 75 and 84 years, and $1.3 \%$ (95\% CI, 0.27 to 2.3 ) per person-year for ages 85 and older. Because so few patients developed vascular dementia, we did not attempt to compute the age-specific incidence rates by ethnic group.

Cumulative incidence and relative risk. We compared the cumulative risk of developing $\mathrm{AD}$ by ethnic group using Cox proportional hazards models adjusting for differences in education and potential confounding variables. Compared with white individuals, the cumulative risk of $\mathrm{AD}$, adjusting for education, was significantly higher for African-American and Caribbean Hispanic individuals (table 3). In separate models, we recalculated the cumulative risk adjusting for a history of diabetes, hypertension, and heart disease among African-American and Hispanic individuals compared with white individuals, but the HR did not change appreciably. A multivariate analysis including simultaneous adjustments for hypertension, heart disease, stroke, diabetes, and years of education also had minimal effects on the HR (see table 3 ). We reanalyzed the main effects, comparing cumulative risk in African-American and Caribbean Hispanic individuals to that in white individuals by limiting the case definition to probable $\mathrm{AD}$; the results remained unchanged (African-Americans: $\mathrm{HR}=$ 3.2, 1.7 to $5.9, p=0.001$; Hispanics: $\mathrm{HR}=2.8,1.5$ to 5.3, $p=0.001$ ). We repeated these analyses using a covariate to indicate those individuals who had received the full neuropsychological battery at the baseline assessment, but the results were unchanged. An analysis including a co- variate for illiteracy was completed, but the results did not change.

Discussion. This community-based study, covering a period of 7 years, provided empirical evidence indicating that the rate of newly acquired $\mathrm{AD}$ is significantly higher among African-American and $\mathrm{Ca}$ ribbean Hispanic individuals than among white individuals at similar ages. Differences in the incidence rates were less pronounced for individuals between the ages of 75 and 84 years of age, but they still remained significantly higher. These higher incidence rates were independent of history of heart disease, stroke, and risk factors for either cardiovascular or cerebrovascular disorders. The differences in incidence rates by ethnic group could not be attributed to variations in the level of education or to the frequency of illiteracy, reducing the possibility that there was a systematic error in diagnosis.

We have previously reported that the age-specific prevalence of $\mathrm{AD}$ was higher in these two ethnic groups compared with white individuals in the same community. ${ }^{8}$ Prevalence is the proportion of affected individuals at a specific point in time, and is an estimate of the disease burden in the population. Incidence rates reflect a more dynamic change in the population because they indicate the number of newly acquired cases developing among previously healthy individuals. Cumulative incidence, or risk, at specific ages should parallel the age-specific prevalence, and the figures reported here appear to be consistent. Thus, not only is the relative proportion of $\mathrm{AD}$ higher in these two ethnic groups compared with white individuals, but the results of this study indicate that the rate at which the disease is acquired is also increased.

The results in white individuals in this community are similar to those in studies from east Boston ${ }^{9}$ and Rotterdam. ${ }^{15}$ For example, in Rotterdam, the age-specific incidence rates were approximately $0.3 \%$ per person-year for persons between the ages of 65 and 74 years, $2.0 \%$ per person-year between ages 75 and 84 years, and 5.2\% per person-year for persons aged 85 years and older (see table 2 for comparison). There has been considerable variation in the published incidence rates for $\mathrm{AD}$, but this has been attributed to differences in the ways in which cases were defined. ${ }^{3}$

Higher rates of $\mathrm{AD}$ among African-American individuals have been ascribed to comorbid cerebrovascular diseases.6,12,25 The frequency of vascular dementia was not significantly higher among African-American and Caribbean Hispanic individuals compared to white individuals in this study, and the rate we report is consistent with that of published reports. ${ }^{21}$ The majority of individuals meeting criteria for vascular dementia had appropriate brain imaging studies confirming their diagnosis. ${ }^{48}$ The cumulative risk of $\mathrm{AD}$ remained significantly higher among African-American and Hispanic individuals compared to white individuals after adjustment for 
the presence of stroke or history of diabetes, hypertension, or heart disease. Therefore, neither clinically apparent cardiovascular or cerebrovascular disease contributed to the higher incidence rates of $\mathrm{AD}$ in African-American and Caribbean Hispanic individuals compared to white individuals. Restricting the analysis to probable $\mathrm{AD}$, excluding comorbid illnesses associated with stroke and cardiovascular disease, also did not change the results. Because we did not have vascular imaging or electrocardiograms available, we cannot exclude the possibility that individuals who developed $\mathrm{AD}$ may have had silent strokes or subclinical cardiovascular disease.

Miller et al. ${ }^{24}$ studied consecutive autopsies over an 18-month period between 1980 and 1982 at an academic medical center in Michigan. They reported no differences in the frequency of neuritic plaques and neurofibrillary tangles, invariable pathologic manifestations of $\mathrm{AD}$, among African-American and white patients, though no systematic clinical information was available. However, de la Monte et al. ${ }^{25}$ reported that these same pathologic manifestations of $\mathrm{AD}$ were more frequent in white individuals than in African-American individuals among consecutive autopsies in patients, regardless of whether the clinical records indicated a history of dementia. They also found significantly more cerebrovascular disease among African-American individuals than among white individuals, concluding that vascular dementia was the most frequent cause of dementia in this group. No clinical evaluations were performed in either study, so clinicopathologic correlation could not be performed. Postmortem studies such as these are objective, but the lack of a detailed assessment of clinical abilities during life makes interpretation difficult. Consent for autopsy also varies considerably by ethnic group. ${ }^{49}$ Confidence in the clinical diagnoses made in this study was buttressed by an earlier report, in which we found the sensitivity and specificity of the diagnosis of $\mathrm{AD}$ in this community study to be high and not to vary by ethnic group..$^{50}$

We previously reported that the risk of developing $\mathrm{AD}$ was increased twofold among individuals with less than 8 years of education or with low occupational attainment. ${ }^{51}$ In our analysis, adjusting or stratifying by education as measured in years of school attendance did not change the differences in the frequency and cumulative risk of $\mathrm{AD}$ across ethnic groups. However, we could not fully explore the interaction between education and ethnic group membership in our study because the frequency of white individuals with little to no education was very low. There are inconsistent results relating $\mathrm{AD}$ risk to level of education, ${ }^{19,23,51-57}$ suggesting that the level of education may be a surrogate for other, as yet unknown, exposures or experiences that occur early in life. ${ }^{54}$ Clearly, the quantity and quality of educational experience can vary dramatically across ethnic groups in the United States. ${ }^{58}$ Furthermore, adjusting for illiteracy in the current study also did not change the results.
Although the frequency of the APOE- $\epsilon 4$ allele, a major genetic risk factor for $\mathrm{AD},{ }^{59,60}$ is higher among individuals in these two ethnic groups, ${ }^{61}$ we can not attribute the increased frequency of disease to this polymorphism. Compared to white individuals without an APOE- $\epsilon 4$ allele, the risk of $\mathrm{AD}$ among African-American and Hispanic individuals was increased by nearly threefold. ${ }^{62}$ Other allelic polymorphisms or gene mutations may contribute to the higher rates of disease in these ethnic groups. ${ }^{63}$

Hispanic individuals represent a very large and diverse cultural group around the world. Thus, our results in Caribbean Hispanic individuals may not generalize to all groups of Hispanics. The majority of Caribbean Hispanic individuals in this community study were from the Dominican Republic. Hispanics from this country and other Caribbean nations may share some of their genetic background with individuals of African descent, which may partially explain the similarity in disease risk. ${ }^{64-66}$ Because the proportion of African-American and Hispanic individuals living beyond age 65 years in the United States is increasing more rapidly than the proportion of white individuals, ${ }^{67}$ it is imperative that this disparity in the rates of disease among the elderly be understood.

\section{References}

1. Bachman DL, Wolf PA, Linn R, et al. Prevalence of dementia and probable senile dementia of the Alzheimer type in the Framingham Study. Neurology 1992;42:115-119.

2. Bachman DL, Wolf PA, Linn RT, et al. Incidence of dementia and probable Alzheimer's disease in a general population: the Framingham Study. Neurology 1993;43:515-519.

3. Breteler MM, Claus JJ, van Duijn CM, Launer LJ, Hofman A. Epidemiology of Alzheimer's disease. Epidemiol Rev 1992;14: $59-82$.

4. Evans DA, Funkenstein HH, Albert MS, et al. Prevalence of Alzheimer's disease in a community population of older persons. Higher than previously reported [see comments]. JAMA1989;262:2551-2556.

5. Fillenbaum GG, Heyman A, Huber MS, et al. The prevalence and 3-year incidence of dementia in older Black and White community residents. J Clin Epidemiol 1998;51:587-595.

6. Folstein MF, Bassett SS, Anthony JC, Romanoski AJ, Nestadt GR. Dementia: case ascertainment in a community survey. J Gerontol 1991;46:M132-M138.

7. Fratiglioni L, De Ronchi D, Aguero-Torres H. Worldwide prevalence and incidence of dementia. Drugs Aging 1999;15: $365-375$.

8. Gurland BJ, Wilder DE, Lantigua R, et al. Rates of dementia in three ethnoracial groups. Int J Geriatr Psychiatry 1999;14: 481-493.

9. Hebert LE, Scherr PA, Beckett LA, et al. Age-specific incidence of Alzheimer's disease in a community population. JAMA 1995;273:1354-1359.

10. Hendrie HC, Hall KS, Pillay N, et al. Alzheimer's disease is rare in Cree. Int Psychogeriatr 1993;5:5-14.

11. Hendrie HC, Osuntokun BO, Hall KS, et al. Prevalence of Alzheimer's disease and dementia in two communities: Nigerian Africans and African Americans [see comments]. Am J Psychiatry 1995;152:1485-1492.

12. Heyman A, Fillenbaum G, Prosnitz B, Raiford K, Burchett B, Clark C. Estimated prevalence of dementia among elderly black and white community residents. Arch Neurol 1991;48: $594-598$.

13. Jorm AF, Jolley D. The incidence of dementia: a metaanalysis. Neurology 1998;51:728-733.

14. Launer LJ, Andersen K, Dewey ME, et al. Rates and risk factors for dementia and Alzheimer's disease: results from EURODEM pooled analyses. EURODEM Incidence Research 
Group and Work Groups European Studies of Dementia. Neurology 1999;52:78-84.

15. Ott A, Breteler MM, van Harskamp F, Stijnen T, Hofman A. Incidence and risk of dementia. The Rotterdam Study. Am J Epidemiol 1998;147:574-580.

16. Perkins P, Annegers JF, Doody RS, Cooke N, Aday L, Vernon $\mathrm{SW}$. Incidence and prevalence of dementia in a multiethnic cohort of municipal retirees. Neurology 1997;49:44-50.

17. Rocca WA, Cha RH, Waring SC, Kokmen E. Incidence of dementia and Alzheimer's disease: a reanalysis of data from Rochester, Minnesota, 1975-1984. Am J Epidemiol 1998;148: 51-62.

18. White L, Petrovitch H, Ross GW, et al. Prevalence of dementia in older Japanese-American men in Hawaii: The HonoluluAsia Aging Study [see comments]. JAMA 1996;276:955-960.

19. Zhang M, Katzman R, Yu E, Liu W, Xiao SF, Yan H. A preliminary analysis of incidence of dementia in Shanghai, China. Psychiatry Clin Neurosci 1998;52(suppl):S291-S294.

20. von Strauss E, Viitanen M, De Ronchi D, Winblad B, Fratiglioni L. Aging and the occurrence of dementia: findings from a population-based cohort with a large sample of nonagenarians. Arch Neurol 1999;56:587-592.

21. Andersen K, Launer LJ, Dewey ME, et al. Gender differences in the incidence of $\mathrm{AD}$ and vascular dementia: the EURODEM Studies. EURODEM Incidence Research Group. Neurology 1999;53:1992-1997.

22. Gao S, Hendrie HC, Hall KS, Hui S. The relationships between age, sex, and the incidence of dementia and Alzheimer disease: a meta-analysis. Arch Gen Psychiatry 1998;55:809815.

23. Letenneur L, Gilleron V, Commenges D, Helmer C, Orgogozo JM, Dartigues JF. Are sex and educational level independent predictors of dementia and Alzheimer's disease? Incidence data from the PAQUID project. J Neurol Neurosurg Psychiatry 1999;66:177-183.

24. Miller FD, Hicks SP, D'Amato CJ, Landis JR. A descriptive study of neuritic plaques and neurofibrillary tangles in an autopsy population. Am J Epidemiol 1984;120:331-341.

25. de la Monte SM, Hutchins GM, Moore GW. Racial differences in the etiology of dementia and frequency of Alzheimer lesions in the brain. J Natl Med Assoc 1989;81:644-652.

26. Hobbs FB, Damon BL. 65+ in the United States. Washington, DC: US Department of Commerce, 1993.

27. Gurland B, Golden RR, Teresi JA, Challop J. The SHORT-CARE: an efficient instrument for the assessment of depression, dementia and disability. J Gerontol 1984;39:166-169.

28. Pittman J, Andrews H, Tatemichi T, et al. Diagnosis of dementia in a heterogeneous population. A comparison of paradigm-based diagnosis and physician's diagnosis. Arch Neurol 1992;49:461-467.

29. Stern Y, Andrews H, Pittman J, et al. Diagnosis of dementia in a heterogeneous population. Development of a neuropsychological paradigm-based diagnosis of dementia and quantified correction for the effects of education. Arch Neurol 1992; 49:453-460.

30. Folstein MF, Folstein SE, McHugh PR. "Mini-mental state": a practical method for grading the cognitive state of patients for the clinician. J Psychiatr Res 1975;12:189-198.

31. Kaplan E, Goodglass H, Weintraub S. Boston Naming Test. Philadelphia, PA: Lea and Febiger, 1983.

32. Benton A. FAS Test. In: Spreen O, Benton A, eds. Neurosensory Center Comprehensive Examination for Aphasia. Victoria, Canada: University of Victoria, 1967.

33. Goodglass H, Kaplan E. Assessment of aphasia and related disorders. Philadelphia, PA: Lea and Febiger, 1983.

34. Wechsler D. WAIS-R Manual. New York, NY: The Psychological Corporation, 1981.

35. Mattis S. Mental status examination for organic mental syndrome in the elderly patient. New York, NY: Grune and Stratton, 1976.

36. Rosen WG. The Rosen Drawing Test. Odessa, FL: Psychological Assessment Resources Inc, 1981.

37. Benton AL. The Benton Visual Retention Test. New York, NY: The Psychological Corporation, 1955.

38. Buschke H, Fuld PA. Evaluating storage, retention, and retrieval in disordered memory and learning. Neurology 1974; 24:1019-1025.
39. Schofield PW, Tang M, Marder K, et al. Consistency of clinical diagnosis in a community-based longitudinal study of dementia and Alzheimer's disease. Neurology 1995;45:2159-2164.

40. McKhann G, Drachman D, Folstein M, Katzman R, Price D, Stadlan EM. Clinical diagnosis of Alzheimer's disease: report of the NINCDS-ADRDA Work Group under the auspices of Department of Health and Human Services Task Force on Alzheimer's Disease. Neurology 1984;34:939-944.

41. Roman GC, Tatemichi TK, Erkinjuntti T, et al. Vascular dementia: diagnostic criteria for research studies. Report of the NINDS-AIREN International Workshop [see comments]. Neurology 1993;43:250-260.

42. Hughes CP, Berg L, Danziger WL, Coben LA, Martin RL. A new clinical scale for the staging of dementia. Br J Psychiatry 1982;140:566-572.

43. Stricks L, Pittman J, Jacobs DM, Sano M, Stern Y. Normative data for a brief neuropsychological battery administered to English- and Spanish-speaking community-dwelling elders. J Int Neuropsychol Soc 1998;4:311-318.

44. Rothman KJ, Greenland S. Modern epidemiology. Philadelphia, PA: Lippincott Willams \& Wilkins, 1998.

45. Klein JP, Moeschberger ML. Survival analysis: techniques for censored and truncated data. New York, NY: SpringerVerlag, 1999.

46. Korn EL, Graubard BI, Midthune D. Time-to-event analysis of longitudinal follow-up of a survey: choice of the time-scale [see comments]. Am J Epidemiol 1997;145:72-80.

47. Grambsch PM, Therneau TM, Fleming TR. Diagnostic plots to reveal functional form for covariates in multiplicative intensity models. Biometrics 1995;51:1469-1482.

48. Moroney JT, Tang MX, Berglund L, et al. Low-density lipoprotein cholesterol and the risk of dementia with stroke. JAMA 1999;282:254-260.

49. Harrell LE, Callaway R, Powers R. Autopsy in dementing illness: who participates? Alzheimer Dis Assoc Disord 1993;7: $80-87$.

50. Massoud F, Devi G, Stern Y, et al. A clinicopathological comparison of community-based and clinic-based cohorts of patients with dementia. Arch Neurol 1999;56:1368-1373.

51. Stern Y, Gurland B, Tatemichi TK, Tang MX, Wilder D, Mayeux R. Influence of education and occupation on the incidence of Alzheimer's disease [see comments]. JAMA 1994;271:10041010.

52. Callahan CM, Hall KS, Hui SL, Musick BS, Unverzagt FW, Hendrie HC. Relationship of age, education, and occupation with dementia among a community-based sample of African Americans. Arch Neurol 1996;53:134-140.

53. Geerlings MI, Schmand B, Jonker C, Lindeboom J, Bouter LM. Education and incident Alzheimer's disease: a biased association due to selective attrition and use of a two-step diagnostic procedure? Int J Epidemiol 1999;28:492-497.

54. Hall KS, Gao S, Unverzagt FW, Hendrie HC. Low education and childhood rural residence: risk for Alzheimer's disease in African Americans. Neurology 2000;54:95-99.

55. Liu HC, Chou P, Lin KN, et al. Assessing cognitive abilities and dementia in a predominantly illiterate population of older individuals in Kinmen. Psychol Med 1994;24:763-770.

56. Teresi JA, Golden RR, Cross P, Gurland B, Kleinman M, Wilder D. Item bias in cognitive screening measures: comparisons of elderly white, Afro-American, Hispanic and high and low education subgroups. J Clin Epidemiol 1995;48:473-483.

57. Unverzagt FW, Hui SL, Farlow MR, Hall KS, Hendrie HC. Cognitive decline and education in mild dementia. Neurology 1998;50:181-185.

58. Manly JJ, Jacobs DM, Sano M, et al. Effect of literacy on neuropsychological test performance in nondemented, educationmatched elders. J Int Neuropsychol Soc 1999;5:191-202.

59. Chartier-Harlin MC, Parfitt M, Legrain S, et al. Apolipoprotein $\mathrm{E}$, epsilon 4 allele as a major risk factor for sporadic early and late-onset forms of Alzheimer's disease: analysis of the 19q13.2 chromosomal region. Hum Mol Genet 1994;3:569574 .

60. Farrer LA, Cupples LA, Haines JL, et al. Effects of age, sex, and ethnicity on the association between apolipoprotein $\mathrm{E}$ genotype and Alzheimer disease. A meta-analysis. APOE and Alzheimer Disease Meta Analysis Consortium [see comments]. JAMA 1997;278:1349-1356. 
61. Tang MX, Maestre G, Tsai WY, et al. Relative risk of Alzheimer disease and age-at-onset distributions, based on APOE genotypes among elderly African Americans, Caucasians, and Hispanics in New York City. Am J Hum Genet 1996;58:574584.

62. Tang MX, Stern Y, Marder K, et al. The APOE-epsilon4 allele and the risk of Alzheimer disease among African Americans, whites, and Hispanics [see comments]. JAMA 1998;279:751755.

63. Romas SN, Mayeux R, Rabinowitz D, et al. The deletion polymorphism and Val1000Ile in alpha-2-macroglobulin and Alzheimer disease in Caribbean Hispanics. Neurosci Lett 2000; 279:133-136.

64. Tycko B, Feng L, Nguyen L, et al. Polymorphisms in the human apolipoprotein-J/clusterin gene: ethnic variation and distribution in Alzheimer's disease [published erratum appears in Hum Genet 1998;102:496]. Hum Genet 1996;98:430 436.

65. Osborne LC, Mason JM. HLA-A/B haplotye frequencies among US Hispanic and African-American populations. Hum Genet 1993;91:326-332.

66. Fraser PA, Yunis EJ, Alper CA. Excess admixture proportion of extended major histocompatability complex haplotypes of Caucasian origin among rheumatoid arthritis associated haplotypes in African Americans and Afro-Caribbeans. Ethn Health 1996;1:153-159.

67. Day JC. Population projections of the United States by age, sex, race, and Hispanic origin: 1995 to 2050. Washington, DC: US Bureau of the Census, Current Population Reports 1996; 25-1130.

\title{
Anatomic dissociation of auditory and visual naming in the lateral temporal cortex
}

\author{
Marla J. Hamberger, PhD; Robert R. Goodman, MD, PhD; Kenneth Perrine, PhD; and Tara Tamny, MA
}

\begin{abstract}
Article abstract-Background and Objective: Visual object naming traditionally has been used to identify cortical areas essential for naming (i.e., word retrieval), and investigators have found critical naming sites in the middle and posterior temporal region in most patients. Based on clinical observation, empirical findings, and the pathophysiology of temporal lobe epilepsy, the authors hypothesized that naming sites identified from auditory cues might also be relevant, and that within the temporal region, these sites would be anatomically distinct and located anterior to naming sites based on visual cues. Methods: Twenty patients requiring resective surgery involving the left (language dominant) temporal lobe underwent pre-resection language mapping using direct cortical stimulation. Visual and auditory naming were tested at lateral temporal sites extending from $1 \mathrm{~cm}$ from the anterior tip to the parietal operculum. Results: Auditory naming was consistently disrupted by stimulation in the anterior temporal lobe, whereas both auditory and visual naming were impaired by stimulation in the posterior temporal region. Conclusions: This pattern may explain why word finding difficulties sometimes arise or worsen following surgical procedures in which the anterior temporal region is resected without language mapping, or when resection is based on mapping that identifies language cortex exclusively using visual tasks. These results suggest that utilization of auditory based naming tasks might improve pre-resection identification of essential language cortex during direct stimulation cortical mapping, as well as noninvasive localization of dysfunction during presurgical cognitive testing.
\end{abstract}

NEUROLOGY 2001;56:56-61

Stimulation-based cortical language mapping is often necessary in patients with intractable epilepsy who are candidates for surgical resection within the language dominant hemisphere. Lateral cortical sites at which electrical stimulation impedes language are considered essential for normal language function and, therefore, are not included in the resection in order to preserve language postoperatively. Although there is some variability in the particular tasks employed during language mapping (e.g., naming, counting, reading), ${ }^{1}$ most investigators rely pri- marily on visual object naming. ${ }^{2-5}$ This consists of asking patients to name pictured items (e.g., bell, escalator) during a brief electrical stimulus. ${ }^{2}$ The rationale for this approach is that visual object naming is impaired in virtually all aphasic syndromes and, therefore, preservation of cortex necessary for object naming should reduce the probability of postoperative aphasia. ${ }^{6}$ Results from investigations using object naming tasks have been used to create "maps" illustrating the cortical distribution of "essential" language areas. ${ }^{3,7}$ Although there is considerable

From the Departments of Neurology (Dr. Hamberger) and Neurological Surgery (Dr. Goodman), College of Physicians and Surgeons, Columbia University; Department of Neurology, New York University (Dr. Perrine); and City College of New York, City University of New York (T. Tamny), New York, NY.

Supported by The National Institute of Neurological Disorders and Stroke (NS35140-01A1) (M.J.H.).

Received May 10, 2000. Accepted in final form September 22, 2000.

Address correspondence and reprint requests to Dr. Marla J. Hamberger, The Neurological Institute, 710 West 168th Street, Box 100, New York, NY 10032; e-mail: mh61@columbia.edu 


\section{Neurology}

\section{Incidence of AD in African-Americans, Caribbean Hispanics, and Caucasians in northern Manhattan}

M.-X. Tang, P. Cross, H. Andrews, et al.

Neurology 2001;56;49-56

DOI 10.1212/WNL.56.1.49

\section{This information is current as of January 9, 2001}

\section{Updated Information \& Services}

References

Citations

Subspecialty Collections

Permissions \& Licensing

Reprints including high resolution figures, can be found at: http://n.neurology.org/content/56/1/49.full

This article cites 54 articles, 13 of which you can access for free at: http://n.neurology.org/content/56/1/49.full\#ref-list-1

This article has been cited by 28 HighWire-hosted articles: http://n.neurology.org/content/56/1/49.full\#\#otherarticles

This article, along with others on similar topics, appears in the following collection(s):

All Cognitive Disorders/Dementia

http://n.neurology.org/cgi/collection/all_cognitive_disorders_dementia All epidemiology

http://n.neurology.org/cgi/collection/all_epidemiology

Alzheimer's disease

http://n.neurology.org/cgi/collection/alzheimers_disease

Incidence studies

http://n.neurology.org/cgi/collection/incidence_studies

Inclusion, Diversity, Equity, Anti-racism, and Social Justice (IDEAS)

http://n.neurology.org/cgi/collection/all_equity_diversity_and_inclusio $\mathrm{n}$

Information about reproducing this article in parts (figures,tables) or in its entirety can be found online at:

http://www.neurology.org/about/about_the_journal\#permissions

Information about ordering reprints can be found online:

http://n.neurology.org/subscribers/advertise

Neurology ${ }^{\circledR}$ is the official journal of the American Academy of Neurology. Published continuously since 1951, it is now a weekly with 48 issues per year. Copyright . All rights reserved. Print ISSN: 0028-3878. Online ISSN: 1526-632X.

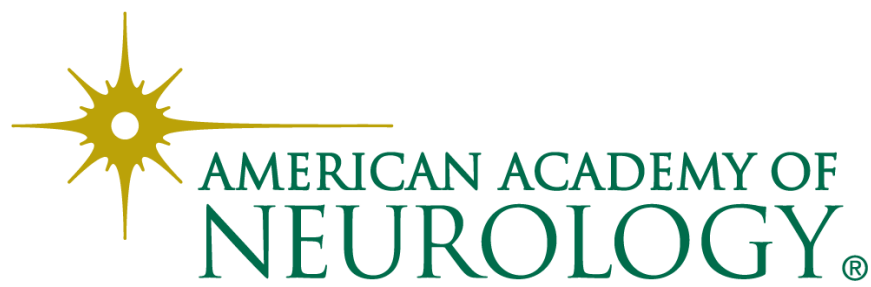

